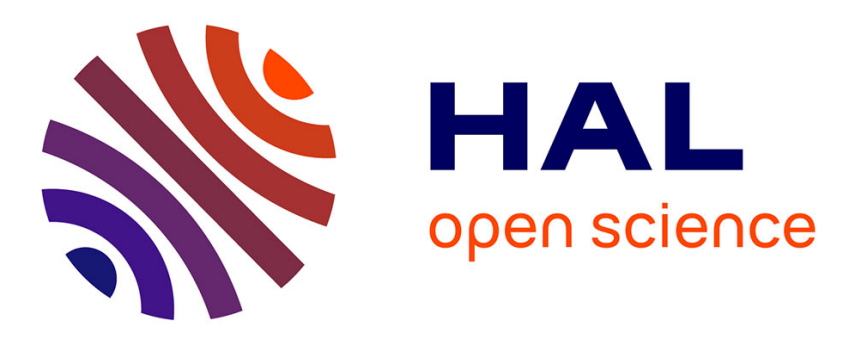

\title{
Truncation effects on muscular fatigue indexes based on M waves analysis
}

Maxime Yochum, Toufik Bakir, Romuald Lepers, Stéphane Binczak

\section{To cite this version:}

Maxime Yochum, Toufik Bakir, Romuald Lepers, Stéphane Binczak. Truncation effects on muscular fatigue indexes based on $\mathrm{M}$ waves analysis. 34th annual international conference of the ieee engineering in medicine and biology society, Aug 2012, san diego, United States. pp.0-0. hal-00764937

\section{HAL Id: hal-00764937 \\ https://hal.science/hal-00764937}

Submitted on 14 Dec 2012

HAL is a multi-disciplinary open access archive for the deposit and dissemination of scientific research documents, whether they are published or not. The documents may come from teaching and research institutions in France or abroad, or from public or private research centers.
L'archive ouverte pluridisciplinaire HAL, est destinée au dépôt et à la diffusion de documents scientifiques de niveau recherche, publiés ou non, émanant des établissements d'enseignement et de recherche français ou étrangers, des laboratoires publics ou privés. 


\title{
Truncation effects on muscular fatigue indexes based on $M$ waves analysis
}

\author{
Maxime Yochum, Toufik Bakir, Romuald Lepers and Stéphane Binczak*
}

13 décembre 2012

\begin{abstract}
Résumé
In this paper, we investigate muscular fatigue. We propose a new fatigue index based on the continuous wavelet transform (CWT) and compare it with the standard fatigue indexes from literature. Fatigue indexes are all based on the electrical activity of muscles (electromyogram) acquired during an electrically stimulated contraction (ES). The stimulator and electromyogram system, which were presented in a previous work, allows real-time analysis. The extracted fatigue parameters are compared between each other and their sensitivity to noise is studied. The effect of truncation of $\mathrm{M}$ waves is then investigated, enlightening the robustness of the index obtained using CWT.
\end{abstract}

\section{INTRODUCTION}

Since last decades, researchers are trying to characterize muscles behavior during contractions. These analysis permit to obtain for instance useful information leading to diagnose muscle diseases [1] [2]. These methods are specially adapted for paralyzed patients as acquired signal analysis could replace usual muscular feeling which is not perceived [3]. The most common signal to extract muscular data is the electromyogram (EMG) [4]. It represents electrical muscular activity of muscular fibers under electrodes. These electrical activities can be acquired during voluntary contractions or during electrical stimulations. Our study is focused on the determination of the muscular fatigue through EMG. Some fatigue indexes are already widely used to estimate the muscular fatigue during contractions. It is the case for the peak to peak (PTP), the root mean square $(\mathrm{RMS})$, the mean $\left(\mathrm{F}_{\text {mean }}\right)$ and the median frequency $\left(\mathrm{F}_{\text {med }}\right)[5-7]$. Those indexes are suitable for electrical contractions obtained with electrostimulators [8]. Our previous studies [9] [10] proposed a new fatigue index based on wavelet computation with continuous wavelet transform (CWT) named $I_{C W T}$. Those indexes are performed in real time during an electrical stimulated contraction thanks to an electrical stimulator

\footnotetext{
${ }^{*}$ M. Yochum, S. Binczak and T. Bakir are with the Laboratoire LE2I UMR CNRS 6306, Universite de Bourgogne, 9 avenue Alain Savary, 21078 Dijon, France. (e-mail: stbinc@u-bourgogne.fr) R. Lepers is with the laboratory INSERM U887, Université de bourgogne, 21078 Dijon cedex, France. (email: romuald.lepers@u-bourgogne.fr)
} 


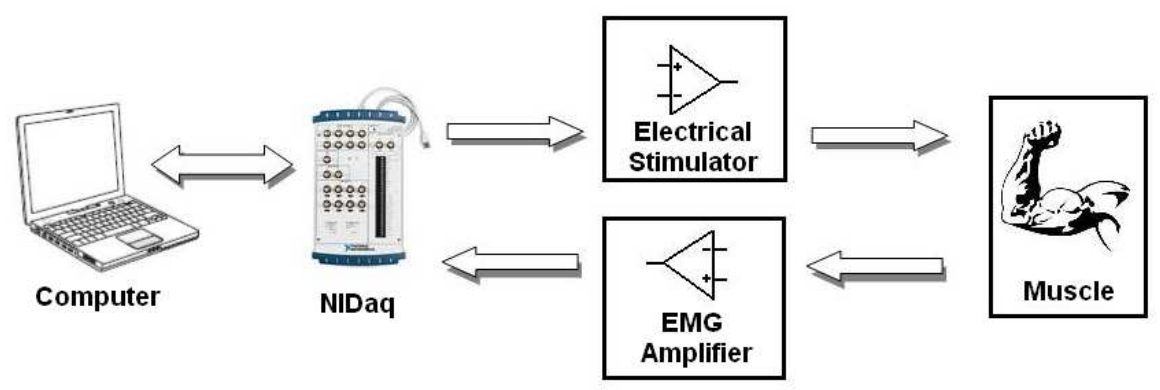

FIGURE 1 - General diagram of the system

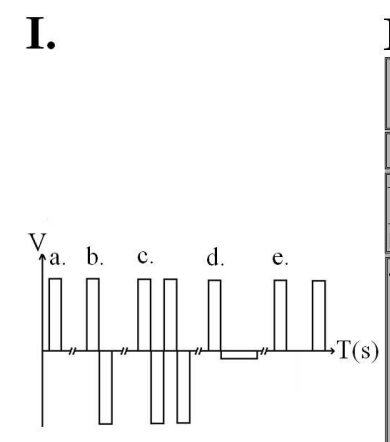

II.

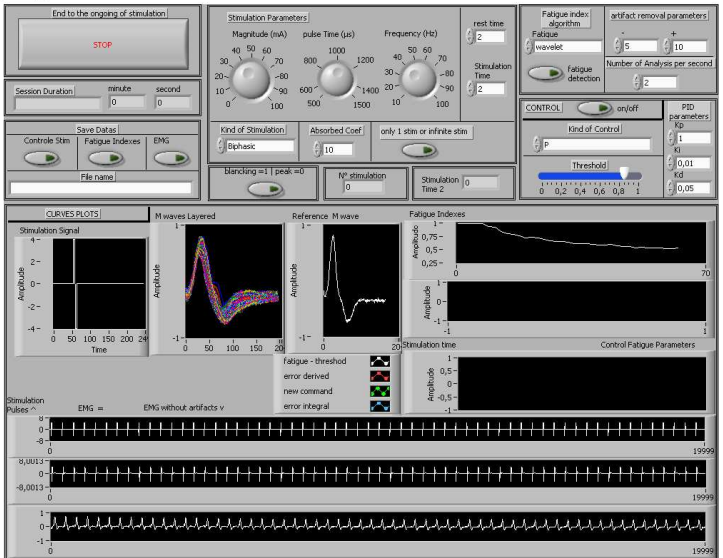

FIGURE 2 - I : Waveforms that can be sent to the stimulation board. a. Monophasic. b. Biphasic. c. Dual Biphasic. d. Absorbed Biphasic. e. doublet Nlet [12]. II : Software interface

delivering constant current pulses. The purpose of this paper is to analyze and compare these fatigue indexes between each other and to check their robustness to noise. Furthermore, this study includes also the influence of truncation which appears in case of high frequency stimulations or when the muscle fatigue becomes large enough during moderate frequency stimulations. Indeed, it is proved that the truncations affect the fatigue algorithms results [11]. Therefore, it is worthwhile to study the influence of truncations on fatigue indexes, which is the main contribution of this paper. 


\section{MATERIAL}

\subsection{Experimental Setup}

The experimental setup is composed of an electrical stimulation circuit and a real time EMG acquisition part [9] [10]. A general diagram of the global system is shown in Fig. 1. The electrical stimulator generates controlled current pulses to have a constant stimulation over time independently of various impedance skin values. It can supply a maximum of $100 \mathrm{~mA}$ for a body impedance of $1.5 \mathrm{~K} \Omega$ between the both stimulation electrodes, a frequency pulse train from $10 \mathrm{~Hz}$ to $100 \mathrm{~Hz}$ and a pulse time from $0.5 \mathrm{~ms}$ to $2 \mathrm{~ms}$ for five different kind of pulse shapes shown in Fig. 2.I. which are the most common ones in literature. The EMG amplifier acquires EMG during the stimulation from bipolar electrodes laid on muscle and a reference electrode. Amplifiers used for the system are INA128 from Texas instruments with a $120 \mathrm{~dB}$ of Common Mode Rejection Ratio (CMRR) yielding a good removal of common voltage of bipolar electrodes. The EMG is used to find $\mathrm{M}$ waves over the stimulation. A software allows to manage stimulation parameters and to estimate the fatigue indexes which are obtained using the algorithms presented in the next section. A screenshot of the software interface is shown in Fig. 2.II. A processing is also included in order to remove stimulation artifacts [9] [10] which are replaced by null values.

\subsection{Fatigue Indexes extraction}

Each fatigue index is computed for each $M$ waves of a stimulation train. The voltage of $\mathrm{M}$ waves is called $\mathrm{V}_{\mathrm{EMG}}(t)$. The fatigue index based on CWT ( $\mathrm{I}_{\mathrm{CWT}}$ ) has been detailed in [9] [10]. Briefly, it gives an estimation of the temporal dilation undergone by $\mathrm{M}$ waves during an electrical stimulation. $\mathrm{I}_{\mathrm{CWT}}$ is computed thanks to the CWT equation

$$
C_{a, b}\left(V_{E M G}, \hat{\psi}(t)\right)=\int_{\mathbb{R}} V_{E M G} \frac{1}{\sqrt{a}} \hat{\psi}\left(\frac{t-b}{a}\right),
$$

where $\hat{\psi}$ is an estimated wavelet obtained from the first $\mathrm{M}$ wave of the stimulation, $a$ is a scale factor (the temporal dilation) and $b$ indicates the temporal location. Then, the $a$ scale parameter is taken such that the corresponding $C_{a, b}\left(V_{E M G}, \hat{\psi}(t)\right)$ reaches its maximum value. Therefore, the $a$ scale parameter represents the temporal dilation of $\mathrm{M}$ wave. The other fatigue indexes from literature tend to decrease over time while the $a$ scale parameter increases. So, in order to keep a common tendency, the fatigue index constructed with parameter $a$ is defined such as

$$
I_{C W T}=\left[\underset{a}{\operatorname{argmax}}\left\{C_{a, b}(s(t), \hat{\psi}(t))\right\}\right]^{-1} .
$$

Four fatigue indexes from literature [5-8] [13] [14] are also implemented. The PTP parameter is related to the amplitude of $\mathrm{M}$ waves and is computed as

$$
P T P=V_{E M G}(\max )-V_{E M G}(\min ) .
$$


The RMS parameter is computed from the total surface area of $\mathrm{M}$ waves, such as

$$
R M S=\sqrt{\sum_{i=0}^{n} V_{E M G} i^{2}} .
$$

The two last fatigue indexes are obtained in the frequency domain. The first one is the mean frequency which is an average of the total power spectrum, computed such as

$$
F_{\text {mean }}=\frac{\sum_{i=0}^{n} P S D_{i} \cdot f_{i}}{\sum_{i=0}^{n} P S D_{i}},
$$

where $P S D$ is the power spectrum density of $\mathrm{V}_{\mathrm{EMG}}$ and $f$ is the frequency vector. The second one is the median frequency, which is the frequency separating the total spectrum density in two identical parts :

$$
\sum_{i=0}^{F_{\text {med }}} P S D_{i}=\sum_{i=F_{\text {med }}}^{n} P S D_{i}=\frac{1}{2} \cdot T S D
$$

where $T S D$ is the total spectrum density.

All previous fatigue indexes are normalized to vary between 0 and 1 . The fatigue indexes are normalized as :

$$
n F_{\text {index }}=\frac{F_{\text {index }}}{\max \left(F_{\text {index }}\right)},
$$

where $F_{\text {index }}$ is the fatigue index among $\mathrm{I}_{\mathrm{CWT}}$, PTP, RMS, $\mathrm{F}_{\text {mean }}$ and $\mathrm{F}_{\text {med }}$. In Fig. 3, an illustration of these fatigue index results are given, which correspond to the experiments presented in the following section. Initially, they all are set to one due to normalization. Then, they all decrease in different ways as the fatigue is increasing during the stimulation. Those changes are linked to physiological changes of muscular fibers [13] [8].

\subsection{Experimental results}

For our experiments, the pulses parameters have been set in order to deliver a biphasic symmetric stimulation with a 30,40,50,60 and $70 \mathrm{~mA}$ intensity, a $1 \mathrm{~ms}$ pulse duration, a 20,30,40,50 and $60 \mathrm{~Hz}$ pulse train frequency and a total duration of stimulation of $10 \mathrm{~s}$. All stimulations have been applied on the biceps brachia isometrically, the position of arm and forearm were fixed. An example of experimental results is shown in Fig. 3. It is interesting to observe the differences of fatigue indexes during several consecutive contractions exercises. In the Fig. 4, fatigue indexes have been plotted for 4 consecutive $10 s$ stimulations with a rest time between two stimulations of $10 s$. For all five fatigue index algorithms, the fatigue becomes more and more important over the stimulation trains. The fatigue index based on CWT follows the same tendency. This decrease to low values could be explained by the fact that the muscle does not have the time to recover its initial condition during the $10 \mathrm{~s}$ of rest, therefore the muscle becomes increasingly tired. 


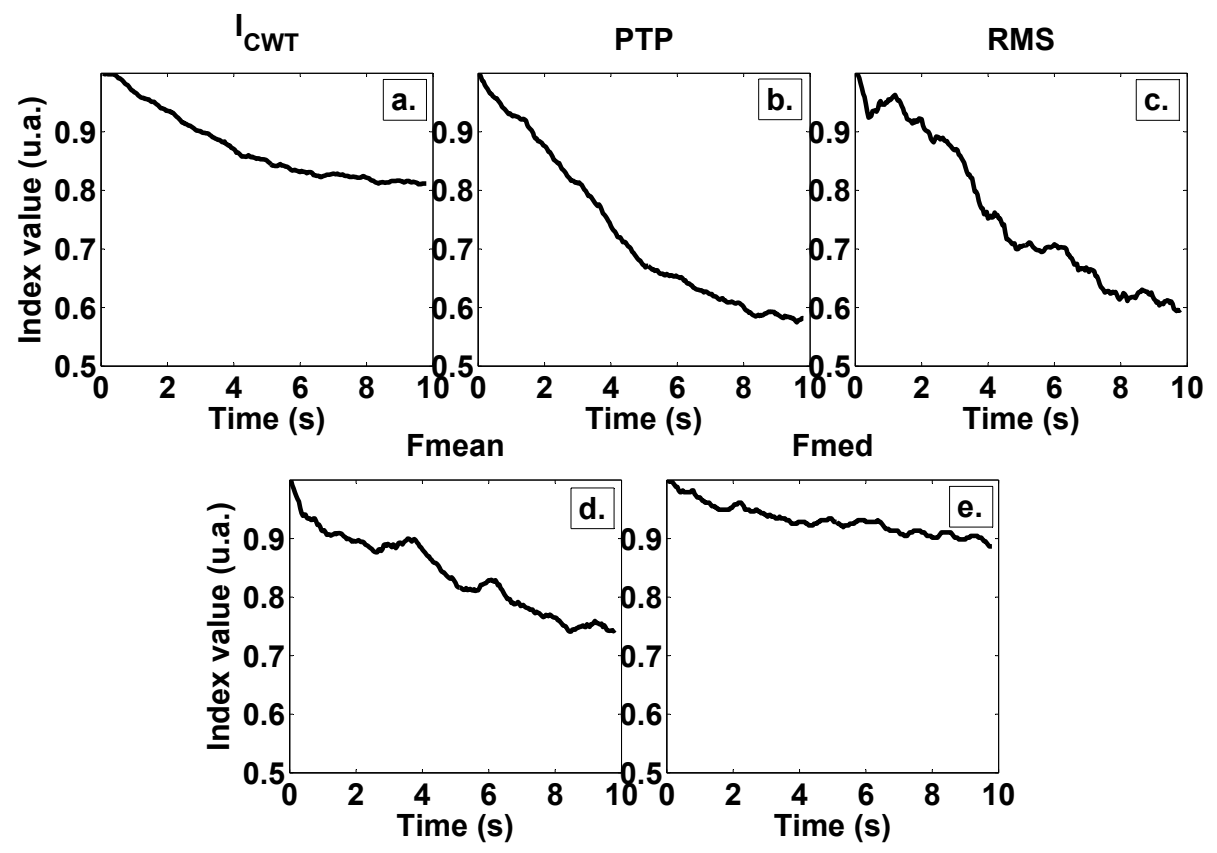

FIGURE 3 - Ewemple of fatigue indexes : a. CWT based ( $\mathrm{I}_{\mathrm{CWT}}$ ), b. Peak to Peak (PTP), c. Root Mean Square (RMS), d. Mean Frequency $\left(F_{\text {mean }}\right)$, e. Median Frequency $\left(F_{\text {med }}\right)$.

\section{EXPERIMENTAL FATIGUE INDEXES COMPARI- SON}

\subsection{Qualitative comparison}

In order to compare $\mathrm{I}_{\mathrm{CWT}}$ to the others fatigue indexes (PTP, RMS, $\mathrm{F}_{\text {mean }}$ and $\mathrm{F}_{\mathrm{med}}$ ), different $X Y$ displays have been plotted as in Fig. 5. The $Y$ axes are the $I_{C W T}$ indexes and the $\mathrm{X}$ axes are the common fatigue indexes. This representation leads to observe the differences between $\mathrm{I}_{\mathrm{CWT}}$ and the other indexes, yielding a qualitative relationship between them. For example, the curves in Fig. 5.a ( $\mathrm{I}_{\mathrm{CWT}}$ with PTP) shows that the results for each stimulation train are different. There is clearly a drift between the two indexes during the experiments. Therefore, there is no trivial correlation between $\mathrm{I}_{\mathrm{CWT}}$ and PTP. We observe the same behavior between $\mathrm{I}_{\mathrm{CWT}}$ and RMS (see Fig. 5.b). As these fatigue indexes are not equivalent, their combination could bring more physiological information when measuring amplitudes, shapes and frequencies aspects of $M$ waves voltages. We can note that the plots c. and d. in the Fig. 5 show that there is a linear relationship between $\mathrm{I}_{\mathrm{CWT}}$ and $\mathrm{F}_{\text {mean }}$. It is more marked with $\mathrm{F}_{\text {med }}$. Indeed, the shape of $\mathrm{M}$ waves is directly related to their frequencies. 
TABLE 1 - Mean absolute error for 5 indexes (\%)

\begin{tabular}{|c|c|c|c|c|c|}
\hline Fatigue index & PTP & RMS & $F_{\text {mean }}$ & $F_{\text {med }}$ & $\mathbf{I}_{\text {CWT }}$ \\
\hline Noisy Signal & 34.29 & 68.61 & 204.48 & 173.18 & $\mathbf{6 . 6 9}$ \\
\hline
\end{tabular}

\subsection{Noise sensitivity}

$V_{E M G}$ are very little signals that can engender a significant noise to signal ratio (NSR). Therefore, it may be useful to study the influence of noise on the process. A noise has been added on $V_{E M G}$ with an arbitrary amplitude of $10 \%$ of the maximum of $V_{E M G}$ values. Then, fatigue algorithms are applied and mean square errors have been computed between the fatigue results without noise and the fatigue results with noise. On table 1, the mean square error is shown for the five fatigue parameters. The error for $\mathrm{I}_{\mathrm{CWT}}$ is rather low compared to the others fatigue indexes. Therefore, $\mathrm{I}_{\mathrm{CWT}}$ is less noise dependent than the standard fatigue indexes, reinforcing the interest to use the waveform of $\mathrm{M}$ waves rather than only the amplitudes or the frequencies.

\subsection{Truncation influence}

During electrical stimulation, $M$ waves are acquired between two stimulation pulses. If the frequencies of the stimulation pulse train are too high, the $\mathrm{M}$ waves are not complete; The end of each $M$ waves is superimposed with the following stimulation pulse. Due to the fact that the stimulation amplitude is much larger than the EMG amplitude and that the electrodes acquire the total signal, it yields the impossibility to extract this EMG part. This phenomenon is called the truncation. Due to the dilation of $\mathrm{M}$ waves during the electrical stimulation, this phenomenon tends to increase over the stimulation. Therefore, it can also occur for moderate stimulation frequencies. In order to check this truncation sensitivity, artificial truncations have been included in $V_{E M G}$ signals. A constant truncation value has been applied for the whole exercise, such as

$$
t M_{\text {wave }}(x)=H\left(l\left(1-\frac{i}{100}\right)-x\right) \cdot M_{\text {wave }},
$$

where $t M_{\text {wave }}$ is the truncated $\mathrm{M}$ wave, $H$ is the Heaviside function, $l$ is the size on the $\mathrm{M}$ wave and $i$ is the applied percentage of truncation. This task is performed for a wide range of truncation values. An example is shown on the Fig. 6 where the evolution of truncation is depicted related to $0 \%, 40 \%, 60 \%$ and $80 \%$ of truncation. The five fatigue indexes computations are then applied on the $t M_{\text {waves }}$ signal. The Fig. 7 shows the results of fatigue estimation for five truncation percentages ( $0 \%, 20 \%, 40 \%, 60 \%$ and $80 \%$ ). We can note that more the truncation is important, worse the results are. It is not surprising because the signals include less and less information if the truncation is higher. However, it is difficult to observe which index is less sensitive to truncations. To quantify this truncation sensitivity, a quadratic error $Q E(t)$ is calculated between the results with truncation and the reference results (which is for $0 \%$ of truncation), as

$$
Q E(t)=\sqrt{\sum_{i=1}^{N}\left(R_{r e f}(i)-R_{t}(i)\right)^{2}},
$$


where $t$ is the percentage of truncation, $N$ is the number of fatigue indexes, $R_{r e f}$ is the reference indexes and $R_{t}$ is the indexes for truncated signal by $t \%$. An example of this quantification is shown on the Fig. 8. We can see that the error for $\mathrm{I}_{\mathrm{CWT}}$ (continuous + line) is the lowest one. Therefore, this fatigue index is the less truncation dependent with respect to the others. It is more interesting to use waveform dilation quantification ( $\mathrm{I}_{\mathrm{CWT}}$ ) for $\mathrm{M}$ waves corrupted by truncation.

\section{CONCLUSION \& DISCUSSION}

This work uses five fatigue indexes computed from experimental $\mathrm{M}$ waves obtained from electromyograms acquired during electrical stimulations. This study discusses about a comparison of several fatigue indexes and their influences of noise and truncation. This study shows that the $\mathrm{I}_{\mathrm{CWT}}$ fatigue index based on wavelet is less noise and truncation dependent than the standard fatigue indexes from literature. This index could be therefore relevant in case of a high noise or truncation level, which can exist in EMG as for high frequency pulse train. In addition we have seen that the dilation of $M$ waves was directly related to the frequencies of $M$ waves and not directly related to the $\mathrm{M}$ waves amplitudes. It should be interesting to verify that the new fatigue index keeps its valuable properties when computed on EMG obtained from different kind of exercises and different muscles.

\section{Références}

[1] A. Labarre-Vila, "Electromyographie de surface et fonction musculaire en pathologie," Revue Neurologique, vol. 162, no. 4, pp. 459-465, 2006.

[2] M. Zwarts, G. Drost, and D. Stegeman, "Recent progress in the diagnostic use of surface EMG for neurological diseases," Journal of Electromyography and Kinesiology, vol. 10, no. 5, pp. 287-291, 2000.

[3] J. Mizrahi, M. Levy, H. Ring, E. Isakov, and A. Liberson, "EMG as an indicator of fatigue in isometrically FES-activated paralyzed muscles," Rehabilitation Engineering, IEEE Transactions on, vol. 2, no. 2, pp. 57-65, 1994.

[4] P. Konrad, "The abc of emg," A Practical Introduction to Kinesiological Electromyography, vol. 1, 2005.

[5] J. Mizrahi, O. Levin, A. Aviram, E. Isakov, and Z. Susak, "Muscle fatigue in interrupted stimulation : effect of partial recovery on force and EMG dynamics," Journal of Electromyography and Kinesiology, vol. 7, no. 1, pp. 51-65, 1997.

[6] D. Tepavac and L. Schwirtlich, "Detection and prediction of FES-induced fatigue," Journal of Electromyography and Kinesiology, vol. 7, no. 1, pp. 39-50, 1997.

[7] N. Chesler and W. Durfee, "Surface EMG as a fatigue indicator during FESinduced isometric muscle contractions," Journal of Electromyography and Kinesiology, vol. 7, no. 1, pp. 27-37, 1997. 
[8] J. Mizmhi, "Fatigue in muscles activated by functional electrical stimulation," Crit. Rev. Phys. Rehabil. Med, vol. 9, no. 2, pp. 93-129, 1997.

[9] M. Yochum, T. Bakir, S. Jacquir, R. Lepers, and S. Binczak, "A Mixed FES/EMG System for Real Time Analysis of Muscular Fatigue," pp. 4882-4885, 32nd Annual International Conference of the IEEE EMBS Engineering in Medicine and Biology Society, 2010.

[10] M. Yochum, T. Bakir, R. Lepers, and S. Binczak, "Quantification of Muscle Fatigue with Wavelet Analysis Based on EMG During Myoelectrical Stimulation," pp. 53-58, Biodevices, 2012.

[11] R. Merletti and L. Lo Conte, "Advances in processing of surface myoelectric signals : Part 1," Medical and Biological Engineering and Computing, vol. 33, no. 3, pp. 362-372, 1995.

[12] Z. Karu, W. Durfee, and A. Barzilai, "Reducing muscle fatigue in FES applications by stimulating with N-let pulse trains," Biomedical Engineering, IEEE Transactions on, vol. 42, no. 8, pp. 809-817, 1995.

[13] N. Dimitrova, J. Hogrel, T. Arabadzhiev, and G. Dimitrov, "Estimate of M-wave changes in human biceps brachii during continuous stimulation," Journal of Electromyography and Kinesiology, vol. 15, no. 4, pp. 341-348, 2005.

[14] C. Thomas, "Fatigue in human thenar muscles paralysed by spinal cord injury," Journal of Electromyography and Kinesiology, vol. 7, no. 1, pp. 15-26, 1997. 

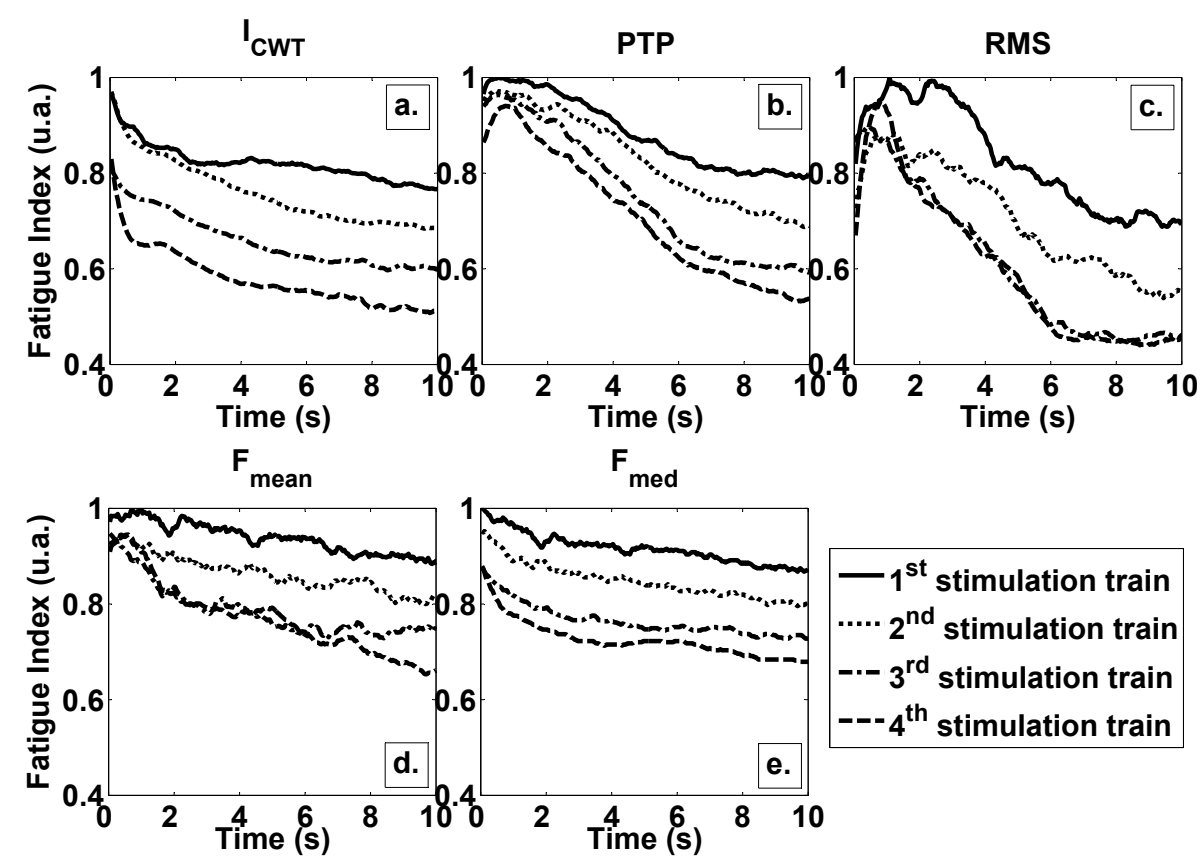

FIGURE 4 - Example of fatigue indexes for 4 consecutive contractions at $10 s$ of stimulation and $10 s$ of rest time : a. $\mathrm{I}_{\mathrm{CWT}}$, b. PTP, c. RMS, d. $\mathrm{F}_{\text {mean }}$, e. $\mathrm{F}_{\text {med }}$. 

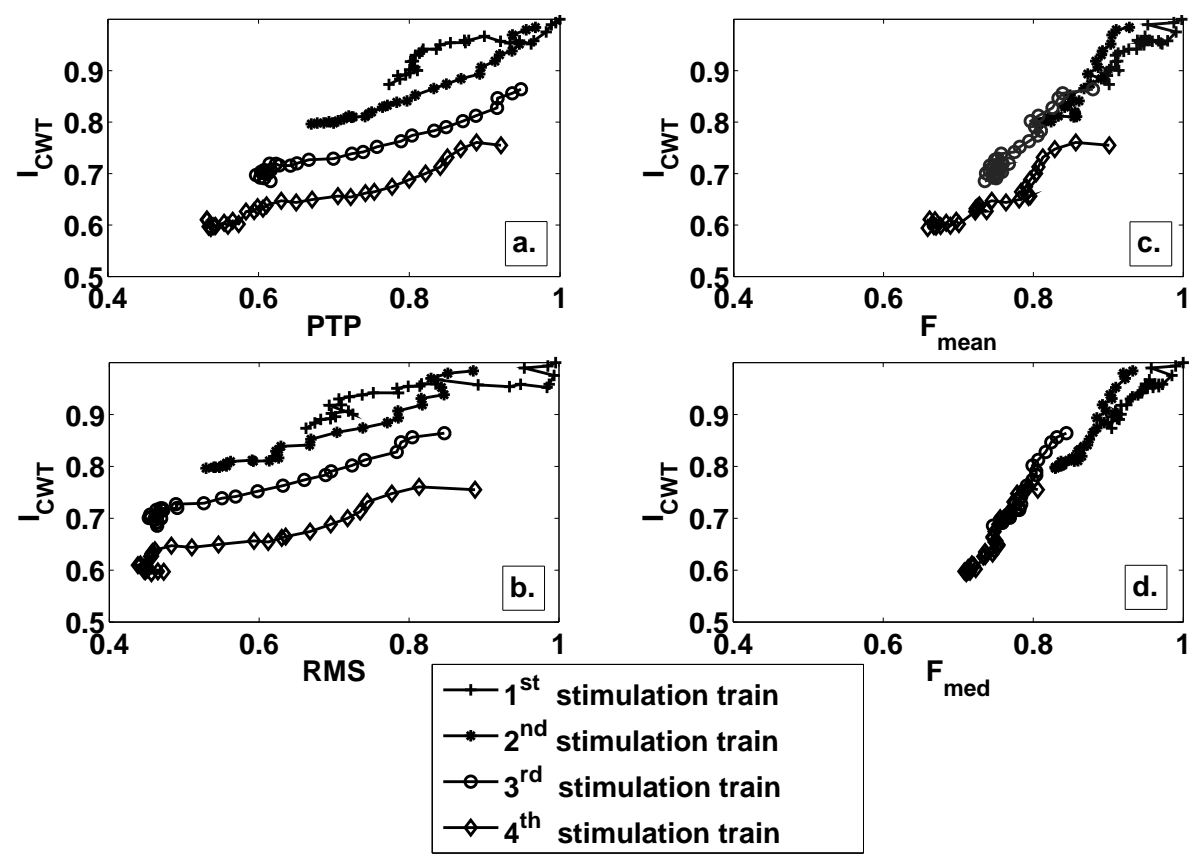

FIGURE 5 - Example of XY curves with : a. $\mathrm{I}_{\mathrm{CWT}}$ and PTP, b. $\mathrm{I}_{\mathrm{CWT}}$ and RMS, c. $\mathrm{I}_{\mathrm{CWT}}$ and $F_{\text {mean }}, \mathrm{d}$. $\mathrm{I}_{\mathrm{CWT}}$ and $\mathrm{F}_{\text {med }}$
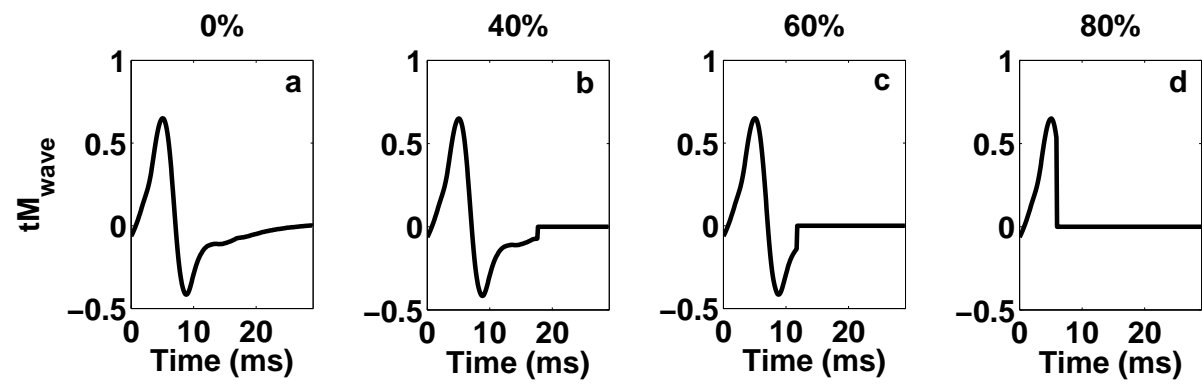

FIGURE 6 - Example of truncation of $\mathrm{M}$ wave for several percentage : a. $0 \%$ b. $40 \%$ c. $60 \%$ d. $80 \%$ 


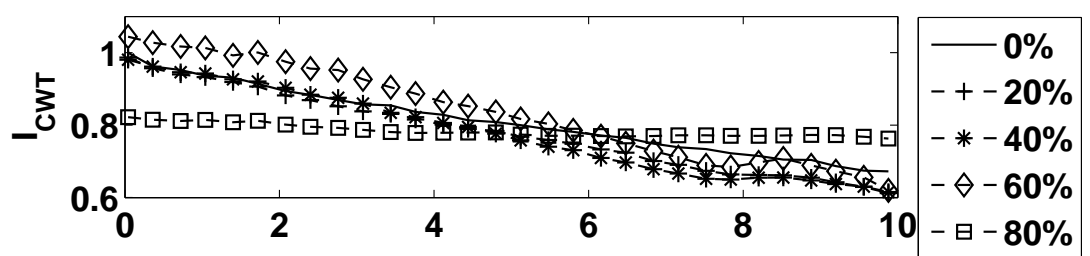

은
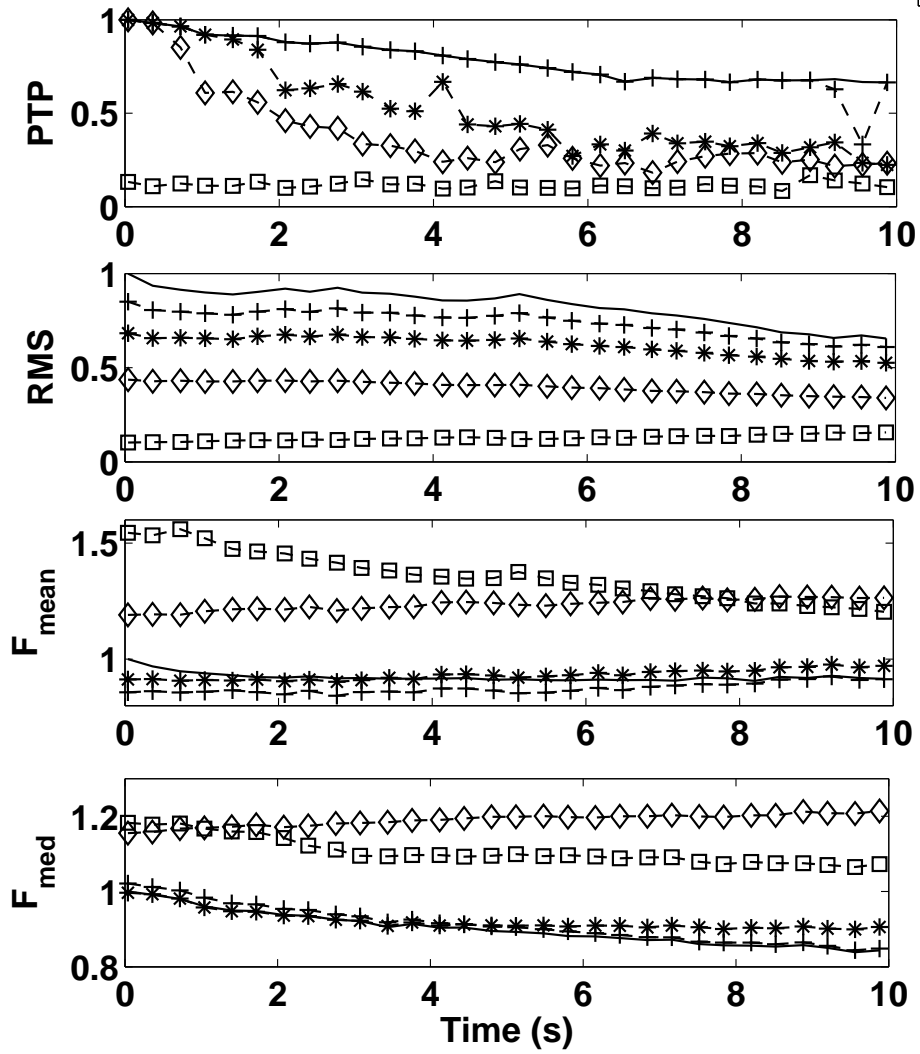

FIGURE 7 - Example of fatigue algorithms results $\left(\mathrm{I}_{\mathrm{CWT}}\right.$, PTP, RMS, $\mathrm{F}_{\text {mean }}$ and $\mathrm{F}_{\text {med }}$ ) for different level of truncation 


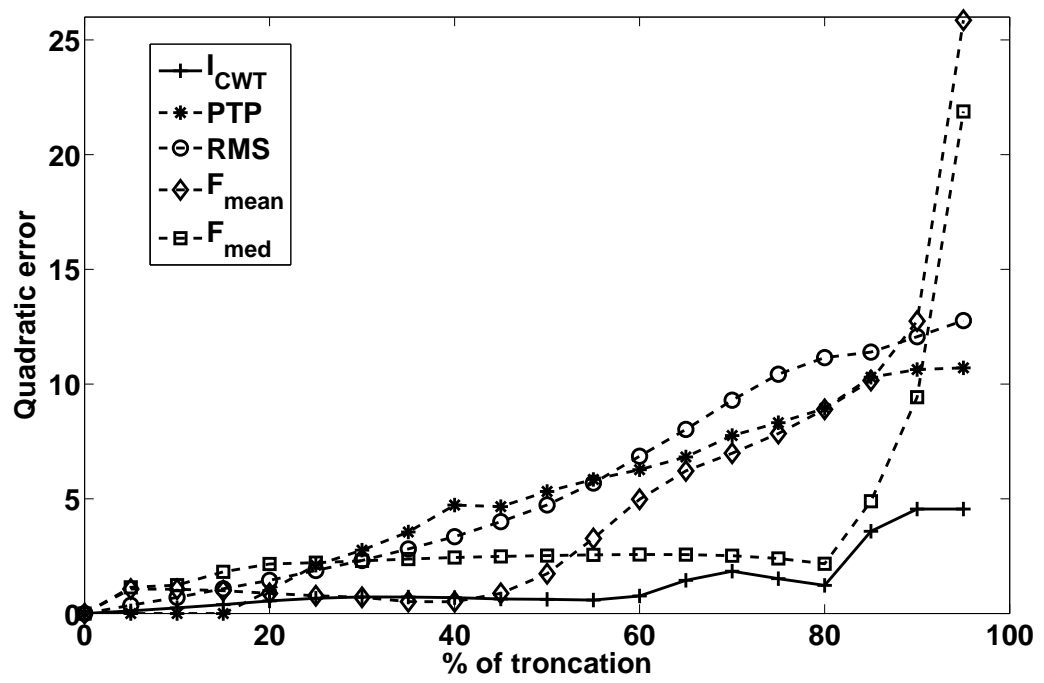

FIGURE 8 - Error of fatigue algorithms results $\left(\mathrm{I}_{\mathrm{CWT}}\right.$, PTP, RMS, $\mathrm{F}_{\text {mean }}$ and $\left.\mathrm{F}_{\text {med }}\right)$ for different level of truncation 